\title{
Teste de ELISA indireto para diagnóstico sorológico de leishmaniose visceral em canídeos silvestres ${ }^{1}$
}

\author{
Paulo R.B. Ferreira ${ }^{2,6 *}$, Daniela F. Larangeiraa ${ }^{2,3}$, Lídia S. de Oliveira², Marcelo de C.C. Malta ${ }^{4}$, \\ Marta C. Gomes ${ }^{4}$, Bruno L. Bastos ${ }^{7}$, Ricardo W. Portela ${ }^{7}$ e Stella Maria Barrouin-Melo ${ }^{2,3}$
}

\begin{abstract}
Ferreira P.R.B., Larangeira D.F., Oliveira L.S., Malta M.C.C., Gomes M.C., Bastos B.L., Portela R.W. \& Barrouin-Melo S.M. 2013. [Indirect ELISA for the serological diagnosis of visceral leishmaniasis in wild canids.] Teste de ELISA indireto para diagnóstico sorológico de leishmaniose visceral em canídeos silvestres. Pesquisa Veterinária Brasileira 33(4):528-534. Laboratório de Infectologia Veterinária, Escola de Medicina Veterinária e Zootecnia, Universidade Federal da Bahia, Av. Adhemar de Barros 500, Salvador, BA 40170110, Brazil. E-mail: paulomev@yahoo.com.br

In South America, some wild canids are considered natural reservoirs of Leishmania chagasi. The immunological response of wild canids to Leishmania is not well understood, and the development of diagnostic methods is necessary for such purpose. In the present study, the standardization of an enzyme-linked immunosorbent assay (ELISA) for the serodiagnosis of visceral leishmaniasis (VL) in Brazilian species of wild canids is described. Serum and plasma samples from 12 captive wild canids were studied: seven from maned wolves (Chrysocyon brachyurus), three from hoary foxes (Lycalopex vetulus), and two from crab-eating foxes (Cerdocyon thous). Samples from C. brachyurus and L. vetulus, both captive in an endemic area for VL, presenting clinical disease and positivity in Indirect Immunofluorescence Reaction and Polymerase Chain Reaction tests were used as positive controls. The antibody anti-dog IgG and Protein A, both conjugated with horseradish peroxidase, were compared in indirect ELISA tests which detected four (04/12) and three $(03 / 12)$ seropositive $C$. brachyurus for anti-Leishmania antibodies, respectively. The ELISA tests were able to clearly distinguish negative from positive samples, as the mean optical density (OD) of the negative samples was 4.8 and 15.5 times lower than those of the positive ones either using anti-dog IgG and Protein A, respectively. Samples from three ELISA - positive C. brachyurus were analyzed by Western blotting and identified immunodominant bands of 19 , $22,24,45$ and $66 \mathrm{kDa}$, among 22 protein bands detected. The ELISAs with protein A and anti-dog IgG showed respectively excellent $(\mathrm{Kappa}=1.0 ; \mathrm{p}<0.001)$ and moderate (Kappa $=0.8 ; \mathrm{p}<0.0015$ ) agreement with the Western blotting assay. The ELISA tests showed to be adequate for screening studies to identify antibody responses, thus indicating contact with Leishmania infection by wild canids.
\end{abstract}

INDEX TERMS: Wild canids, Leishmania, visceral leishmaniasis, ELISA, protein A.

RESUMO.- Na América do Sul, alguns canídeos silvestres são considerados reservatórios naturais da Leishmania chagasi. A resposta imunológica desses animais à Leishma-

\footnotetext{
${ }^{1}$ Recebido em 15 de setembro de 2012.

Aceito para publicação em 14 de março de 2013.

${ }^{2}$ Laboratório de Infectologia Veterinária, Escola de Medicina Veterinária e Zootecnia (EMVZ), Universidade Federal da Bahia (UFBA), Av. Adhemar de Barros 500, Salvador, BA 40170-110, Brasil. *Autor para correspondência:paulomev@yahoo.com.br

${ }^{3}$ Departamento de Patologia e Clínicas, Escola de Medicina Veterinária e Zootecnia (EMVZ), UFBA, Salvador, BA.
}

nia é pouco conhecida, havendo a necessidade de métodos diagnósticos adequados para esse fim. No presente estudo, é descrita a padronização do ensaio imunoenzimático indi-

\footnotetext{
${ }^{4}$ Fundação Zoobotânica de Belo Horizonte (FZB-BH), Av. Afonso Pena 1212, Centro, Belo Horizonte, MG 30130-003, Brasil.

${ }^{5}$ Veterinário autônomo, Rua Desembargador José Marciel dos Santos 7, Quadra A, IAPI, Salvador, BA 40330-475.

${ }^{6}$ Parque Zoobotânico Getúlio Vargas (PZGV), Rua Alto de Ondina s/n, Ondina, Salvador, BA 40170-110.

${ }^{7}$ Laboratório de Imunologia e Biologia Molecular, Instituto de Ciências da Saúde, UFBA, Av. Reitor Miguel Calmon, Salvador, BA 40110-100.
} 
reto (ELISA) para o diagnóstico sorológico de leishmaniose visceral em canídeos silvestres brasileiros. Foram estudadas amostras de soro e plasma de 12 canídeos cativos: sete lobos-guará (Chrysocyon brachyurus), três raposinhas (Lycalopex vetulus) e dois cachorros-do-mato (Cerdocyon thous). As amostras de um C. brachyurus e uma L. vetulus, cativos em área endêmica para LV, que apresentavam doença clínica e positividade em testes de Imunofluorescência Indireta e Reação em Cadeia de Polimerase, foram utilizadas como controles positivos. Foram comparados os conjugados anti-IgG de cão e proteína $\mathrm{A}$, ambos ligados a peroxidase, cujos testes detectaram quatro $(04 / 12)$ e três (03/12) C. brachyurus soropositivos para anticorpos anti-Leishmania sp., respectivamente. As médias das densidades ópticas (DOs) das amostras negativas foram nitidamente mais baixas do que as médias das DOs dos positivos tanto no ELISA com anti-IgG de cão ( 4,8 vezes) como com proteína A (15,5 vezes). Os soros de três $C$. brachyurus positivos no ELISA indireto foram avaliados por Western blotting e identificaram 22 bandas, sendo imunodominantes as de peso molecular de 19,22, 24, 45 e $66 \mathrm{kDa}$. Os testes ELISA com a proteína A e o conjugado anti-IgG de cão apresentaram respectivamente concordância excelente (Kappa $=1 ; \mathrm{p}<0,001)$ e moderada (Kappa $=0,8 ; \mathrm{p}<0,0015)$, com o Western blotting. Ambos foram, portanto, considerados adequados a avaliações de triagem de animais cuja resposta humoral de anticorpos indica contato com o parasito, úteis para subsidiar estudos para adequação de metodologias específicas para os canídeos silvestres.

TERMOS DE INDEXAÇÃO: Canídeos silvestres, Leishmania, leishmaniose visceral, ELISA, Proteína A.

\section{INTRODUÇÃO}

A leishmaniose visceral (LV) é uma metazoonose de humanos e canídeos, causada nas Américas por Leishmania chagasi. A referida espécie é considerada geneticamente idêntica $L$ infantum, que na Europa causa quadro clínico e resposta imunológica semelhantes aos descritos em canídeos no Brasil . 0 cachorro-do-mato (Cerdocyon thous) é considerado reservatório silvestre da LV no Brasil, onde a infecção é transmitida para os hospedeiros através da picada de Lutzomyia longipalpis ou L. cruzi. Estudos recentes confirmaram também a presença de Leishmania sp. em lobo-guará - Cerdocyon brachyurus e cachorro-vinagre - Speothos venaticus mantidos em conservação ex situ (Courtenay et al. 1996, Maurício et al. 1999, Brasil 2005, Luppi et al. 2008, Lima et al. 2009, Souza et al. 2010, De Almeida et al. 2011, Jusi et al. 2011).

Uma limitação à padronização de testes sorológicos para as diversas espécies de canídeos selvagens é a falta de conjugados específicos. A utilização de conjugados à base de imunoglobulinas anti-IgG de cão doméstico ligadas a enzimas como a peroxidase é descrita para a pesquisa de anticorpos anti-Leishmania sp. em ensaios imunoenzimáticos para C. thous (Courtenay et al. 2002), S. venaticus (Jusi et al. 2011), Vulpes vulpes (Mancianti, Mignone \& Galestri 1994) e C. brachyurus (Curi, Miranda \& Talamoni 2006). Tal utilização baseia-se na propriedade de ligação cruzada, de- vido à semelhança genética entre indivíduos pertencentes à mesma família. (Zrzavy \& Ricancova 2004).

Conjugados à base de proteína A ligada a enzimas representam uma alternativa no desenvolvimento de testes sorológicos para animais silvestres, conforme descrito para o cachorro-vinagre (S. venaticus). A proteína A é um conjugado polivalente, obtido a partir da bactéria Staphylococcus aureus que, no ELISA, liga-se inespecificamente às diferentes classes de imunoglobulinas, no caso, ligadas a antígenos de Leishmania sp. adsorvidos na fase sólida . Esta proteína possui uma boa afinidade com IgG de diferentes espécies de mamíferos silvestres e exóticos (Kelly et al. 1993, Stöbel et al. 2002, Solano-Gallego et al. 2003, Lima et al. 2005).

0 presente estudo teve como objetivo comparar diferentes conjugados em métodos de ELISA padronizados para o diagnóstico sorológico de infecção por Leishmania sp. em três espécies de canídeos do Brasil. Foram comparadas as reatividades produzidas pelos conjugados à base de anticorpo anti-IgG de cão doméstico e Proteína A marcados com a peroxidase no teste ELISA indireto.

\section{MATERIAL E MÉTODOS}

\section{Animais e aspectos éticos e legais}

Foram estudados 10 canídeos silvestres, sete Chrysocyon brachyurus e três Lycalopex vetulus, cativos na Fundação Zoobotânica em Belo Horizonte, Minas Gerais, Brasil. A instituição é situada em área endêmica para a LV, local com ocorrência de infecção por Leishmania associada à sintomatologia clínica com morte de dois animais (Luppi et al. 2008). Foram incluídos no estudo dois C. thous em conservação ex situ no Parque Zoobotânico Getúlio Vargas, Salvador, Bahia, Brasil, considerada área não endêmica. Os animais foram mantidos em recintos de acordo com as Instruções Normativas $n^{\circ}$ 04/2002 e 169/2008 do IBAMA.

Todos os procedimentos com os animais foram realizados pelos médicos veterinários dos zoológicos, em respeito aos aspectos éticos e legais, presentes no Artigo 32, da Lei Federal no 9.605 de 1998 (Lei de Crimes Ambientais, Brasil).

\section{Exame clínico e amostras biológicas}

Os animais foram clinicamente examinados para a presença, frequência e intensidade de sinais clínicos associados a LV e aos sinais clínicos de outras patologias., antes de serem submetidos à coleta de sangue. As amostras de sangue periférico foram obtidas da veia cefálica ou jugular, mantidas em tubos com ou sem anticoagulante (EDTA) em recipiente com gelo, até processamento em laboratório para separação de plasma ou soro respectivamente, sendo estes mantidos em freezer a $-20^{\circ} \mathrm{C}$.

Um dos C. brachyurus (indivíduo 1) estudado, apresentava resultado positivo prévio em PCR e IFI para infecção por Leishmania sp. e já manifestara quadro clínico compatível com LV, sendo suas amostras sorológicas utilizadas como controle positivo para a padronização dos testes ELISA.

\section{Obtenção de antígeno utilizado no ensaio de ELISA}

As formas promastigotas de Leishmania chagasi foram isoladas de cães doentes e caracterizadas por eletroforese de isoenzimas (Biomanguinhos, Fiocruz-IOC, Brasil, LTCC - Leishmania Typing Culture Collection - WDCM731). A amostra foi cultivada em meio Schneider (Sigma Chemical Co) suplementado com $20 \%$ de soro fetal bovino (Gibco, BRL). Para a obtenção do lisado total antigênico, culturas do parasito foram submetidas a ultrassom em 10 ciclos de um minuto em e, centrifugadas a $10.000 \mathrm{xg}$, a $4^{\circ} \mathrm{C}$ por 
10 minutos, sendo o sobrenadante separado e dialisado três vezes com solução salina tamponada com fosfato estéril pH 7.4. Após a dosagem de proteínas, o antígeno foi aliquotado e armazenado a $-20^{\circ} \mathrm{C}$.

\section{ELISA indireto com soros-padrão de cães domésticos}

0 ensaio de ELISA para cães domésticos utilizado como referência para padronização do ELISA para canídeos silvestres foi realizado de acordo com técnica descrita previamente (Paranhos-Silva et al. 1996), com modificações. Foi realizada titulação em bloco com soros de 20 cães portadores de infecção natural, assim como de 20 cães sadios, não infectados e de região não endêmica, amostras utilizadas como soros-padrão. Microplacas de poliestireno (Perkin Elmer Spectra Plate ${ }^{\mathrm{TM}}$ - TC 96, Waltham, EUA) foram sensibilizadas com antígeno de Leishmania, nas concentrações de 1,5 $\mu \mathrm{g} / \mathrm{mL}, 2,5 \mu \mathrm{g} / \mathrm{mL}, 5,0 \mu \mathrm{g} / \mathrm{mL}$ e $10,0 \mu \mathrm{g} / \mathrm{mL}$ em tampão carbonato-bicarbonato a 0,05 M, pH 9,6. Após 12 horas de incubação a $4^{\circ} \mathrm{C}$, as placas foram lavadas com PBS, pH 7.4. O bloqueio foi feito com $200 \mu \mathrm{L} /$ poço de PBS, contendo 0,05\% de Tween 20 (PBS-T) e $5 \%$ de leite em pó desnatado, por $1 \mathrm{~h}$ à temperatura ambiente $\left(22^{\circ} \mathrm{C}\right)$, seguido de quatro lavagens com água destilada. Em seguida, foram adicionadas as amostras de soros no volume de $100 \mu \mathrm{L} /$ poço diluídos a 1:125; 1:250; 1:500; 1:1.000 em PBS-T com $5 \%$ de leite em pó desnatado. Após 1 hora de incubação à temperatura ambiente, as placas foram lavadas e em seguida adicionados $100 \mu \mathrm{L} /$ poço de imunoglobulina de coelho anti-IgG de cão conjugada à peroxidase (Sigma, USA), diluída a 1:6.250; 1:12.500; 1:25.000; 1:50.000 em PBS-T com 0,05\% de leite em pó desnatado. Após incubação por 1 hora à temperatura ambiente, foram feitas quatro lavagens. A revelação foi feita com $100 \mu \mathrm{L} /$ poço de solução contendo peróxido de hidrogênio a 0,03\% e orto-fenilenoldiamina (OPD) (Sigma, USA) em tampão citrato-fosfato (ácido cítrico $-\mathrm{C}_{6} \mathrm{H}_{8} \mathrm{O}_{7}$ a $0.1 \mathrm{M}$; fosfato de sódio - $\mathrm{NaH}_{2} \mathrm{PO}_{4}$ a $0.2 \mathrm{M}$ ) pH 5.1, em ambiente escuro à temperatura ambiente. A reação foi interrompida com $25 \mu \mathrm{L}$ de ácido sulfúrico $4 \mathrm{~N}$ por poço e a placa lida imediatamente em espectrofotômetro com filtro de $492 \mathrm{~nm}$. Todas as amostras foram testadas em triplicata. As condições ótimas concernentes às diluições de antígeno, soro e conjugado foram estabelecidas pela maior razão entre a média de densidade óptica das amostras positivas e a média das amostras negativas.

\section{ELISAs indiretos com soros dos canídeos silvestres}

Dois soros de C. brachyurus, um controle positivo (PCR positivo) e um controle negativo (PCR negativo), foram utilizados em titulação em bloco para definição das condições ótimas do ensaio no discernimento entre soropositivos e soronegativos. Um pool de soros de cães domésticos de área endêmica, com diagnósticos sorológico e parasitológico positivos para LV, foi utilizado como controle positivo. 0 controle negativo foi definido com um pool de soros de cães domésticos, sem sinais clínicos da doença, de uma região sem casos autóctones para a LV, com diagnósticos sorológico, parasitológico e molecular negativos para a doença ou infecção. As amostras de soro foram testadas em triplicatas nas diluições $1: 125 ; 1: 250 ; 1: 500$ e 1:1.000. 0 conjugado anti-IgG de cão com peroxidase (Sigma, USA) foi testado a 1:6.250; 1:12.500; 1:25.000; 1:50.000, ambos em PBS-T com 5\% de leite em pó desnatado, em microplacas sensibilizadas com antígeno de Leishmania na concentração de $5,0 \mu \mathrm{g} / \mathrm{mL}$.

Com as mesmas condições de sensibilização da placa e controles positivos e negativos da titulação em bloco em ELISA descrita anteriormente, foi realizado um ensaio com a substituição da imunoglobulina anti-IgG de cão doméstico por Proteína A conjugada à peroxidase conforme descrito previamente (Lima et al. 2005, Silva et al. 2005, Fattori \& Lima 2007), com modificações.
As amostras de soro foram testadas em triplicatas nas diluições $1: 125 ; 1: 250 ; 1: 500 ; 1: 1.000$ e a proteína A conjugada à peroxidase (Zymed, USA) nas diluições 1:8.000, 1:16.000, 1:32.000 e 1:64.000, ambos diluídos em PBS-T com 5\% de leite em pó desnatado, em microplacas sensibilizadas com antígeno de Leishmania na concentração de 5,0 $\mu \mathrm{g} / \mathrm{mL}$.

Após a definição das condições ótimas de ensaio, os soros dos doze animais foram testados em placas separadas, com ambos os conjugados.

\section{Western blotting para detecção de bandas antigênicas identi- ficadas por anticorpos anti-Leishmania sp.}

A técnica de Western-Blotting foi realizada de acordo com o teste padronizado por Oliveira et al. (2005) com modificações. 0 antígeno solúvel de Leishmania sp foi separado por um sistema SDS-PAGE descontínuo em gel de poliacrilamida (gel de empilhamento: $4 \%$; gel de corrida: $12,5 \%$ ) e as proteínas foram transferidas para uma membrana de nitrocelulose. 0 bloqueio foi feito com PBS-T com 5\% de leite em pó desnatado. As amostras de soro foram diluídas a 1:50 em PBS-T contendo 1\% de leite em pó desnatado e incubadas durante $1 \mathrm{~h}$ a $37^{\circ} \mathrm{C}$. Após cinco lavagens com PBS-T $0,05 \%$, foi adicionado o conjugado anti-IgG de cão com peroxidase (Sigma, USA) na diluição de 1:250 em PBS-T e incubado por $1 \mathrm{~h}$ a $37^{\circ} \mathrm{C}$. Após cinco lavagens, a revelação foi feita com o cromógeno 4-cloro-a-Naftol a 0,3\% diluído em 1:5 em PBS e 10mL de água oxigenada. A reação foi interrompida com a adição de água destilada.

\section{Análise dos dados}

Foi construído um banco de dados contendo a identificação dos animais, características clínicas, resultados dos exames laboratoriais, histórico clínico e as médias e desvios padrão das DOs produzidas nos ensaios imunoenzimáticos. 0 ponto de corte foi definido pela média do controle negativo mais três vezes o desvio padrão (Paranhos-Silva et al. 1996). 0 software SPSS Statitics v.18.0 (IBM®) foi usado para calcular o coeficiente de correlação de Spearman entre as DOs produzidas nos três ensaios sorológicos. 0 valor de significância adotado foi de $p<0,05$.

A repetitividade (RP) foi calculada pelo teste dos controles positivo e negativo de lobo-guará, 40 vezes cada controle, nos ensaios com ambos os conjugados no mesmo dia sob as mesmas condições, e foi calculada de acordo com a seguinte fórmula: RP $=(1-\mathrm{CV}) \times 100$, sendo CV correspondente ao coeficiente de variação (Rebouças et al. 2011). Para determinação da melhor diluição dos soros-padrão e dos conjugados foram considerados os menores valores das DOs dos brancos obtidas em cada ensaio e a melhor razão entre os controles positivo e negativo. A concordância entre os testes sorológicos e a reprodutibilidade da leitura do teste ELISA foi determinada pelo índice de Kappa e interpretada de acordo com Shrout (1998), considerando $\mathrm{k}<0,1$, ausente; $\mathrm{k}=0,10-0,40$, fraca; $\mathrm{k}=0,41-0,60$, discreta; $\mathrm{k}=0,61-0,80$, moderada; e $\mathrm{k}=0,81-1,00$, substancial.

\section{RESULTADOS}

No presente estudo, houve a constatação de sinais clínicos indicativos de LV em 50\% (6/12) dos canídeos silvestres avaliados por meio de exame físico. Foram observadas evidências de esplenomegalia em 57,1\% (4/7) dos Chrysocyon brachyurus. No mesmo grupo de animais, 50\% (2/4) também apresentaram linfoadenomegalia dos linfonodos pré-escapulares. Ainda foram constatadas lesões cutâneas em um Lycalopex vetulus, bem como secreção purulenta vulvar em outro indivíduo da mesma espécie, entretanto ambos 
se mostraram soronegativos nos testes ELISA. As condições ótimas padronizadas no ELISA indireto com amostras de soro de cães domésticos foram: concentração de antígeno de $5 \mu \mathrm{g} / \mathrm{mL}$, diluição dos soros a 1:500 e do conjugado anti-IgG de cão com peroxidase a 1: 25.000. A titulação em bloco realizada com os soros-padrão de $C$. brachyurus e conjugado anti-IgG de cão com peroxidase definiram como condições ótimas a diluição a 1:25.000 e 1:500 do conjugado e soro respectivamente. Nessas condições obteve-se uma razão de 19,29 entre as D0s dos controles positivo e negativo, com a leitura da DO do branco em 0,066. A titulação em bloco com a utilização Proteína A com peroxidase como conjugado definiu as melhores diluições em 1:500 do soro e 1:16.000 do conjugado, que possibilitaram uma razão de 8,06 entre as DOs dos controles positivo e negativo, com o valor da D0 do branco de 0,049 . Os ELISAs com ambos os conjugados apresentaram correlações positivas entre si, sendo capaz de diferenciar os animais positivos dos negativos.

No teste ELISA indireto que avaliou os 12 canídeos silvestres, quatro $C$. brachyurus foram positivos com o uso do conjugado anti-IgG de cão (Fig. 1), e três com a proteína A nas diluições de 1:8.000 e 1:16.000 (Fig. 2 e 3). Assim, um $C$. brachyurus da FZB-BH (indivíduo 7), que apresentou uma leitura de DO acima do ponto de corte no ensaio com o anti-IgG de cão ( $D O=0,300$, ponto de corte $=0,180$ ), também apresentou leitura de DO limítrofe, mas na zona de negatividade, nos testes que utilizaram proteína A nas diluições tanto a 1:8.000 (DO $=0,416$ : ponto de corte $=0,368)$ quanto a 1:16.000 (DO $=0,298$ : ponto de corte $=0,293)$. Um $C$. brachyurus (indivíduo 5) da FZB, positivo nos testes IFI e PCR, apresentou também soropositividade nos ELISAs com ambos os conjugados, além de sinais clínicos como esplenomegalia e linfoadenomegalia. Em contraposição, uma $L$. vetulus (indivíduo 8), também com PCR e IFI positivas para a infecção, apresentou leitura soronegativa nos ELISAs com ambos os conjugados, mas positiva no Western blotting. 0

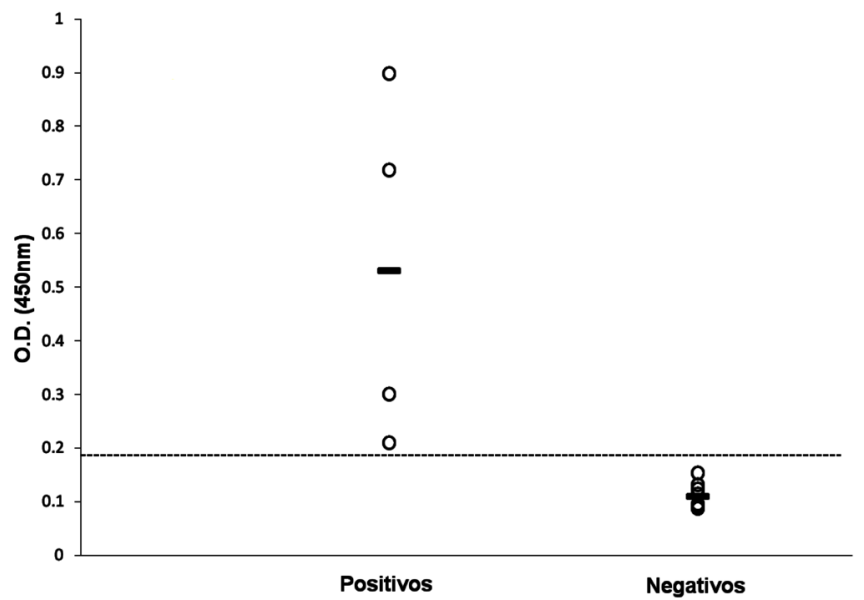

Fig.1. Distribuição dos resultados individuais dos soros de canídeos silvestres submetidos à ELISA indireto para detecção de anticorpos especificos anti-Leishmania, usando o conjugado anti-IgG de cão com peroxidase. Cada círculo representa o resultado de um animal testado, e as barras a média de cada grupo, positivo ou negativo. A linha tracejada indica o cut-off calculado, usando o método de Frey et al. (1998).

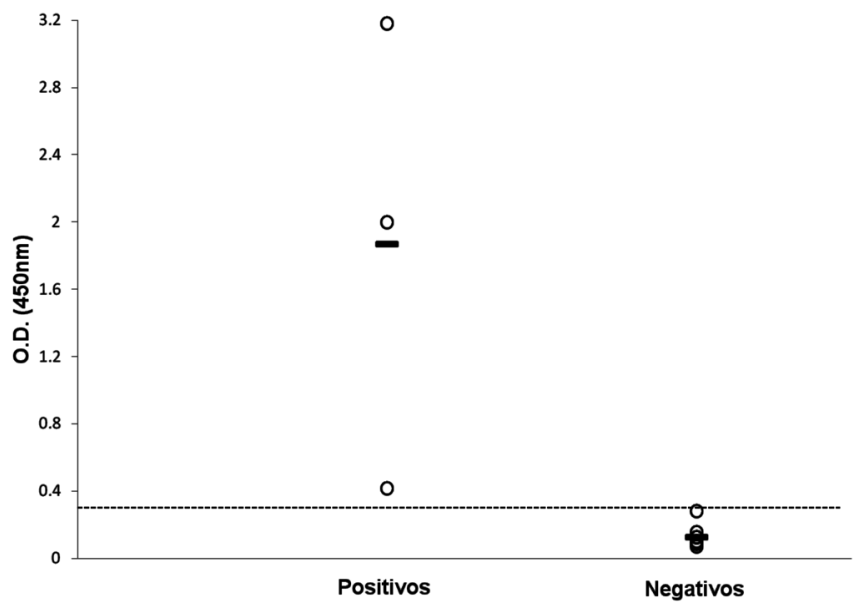

Fig.2. Distribuição dos resultados individuais dos soros de canídeos silvestres submetidos à ELISA indireto para detecção de anticorpos específicos anti-Leishmania, usando o conjugado Proteína A com peroxidase, na diluição de 1:8.000. Cada círculo representa o resultado de um animal testado, e as barras a média de cada grupo, positivo ou negativo. A linha tracejada indica o cut-off calculado, usando o método de Frey et al. (1998).

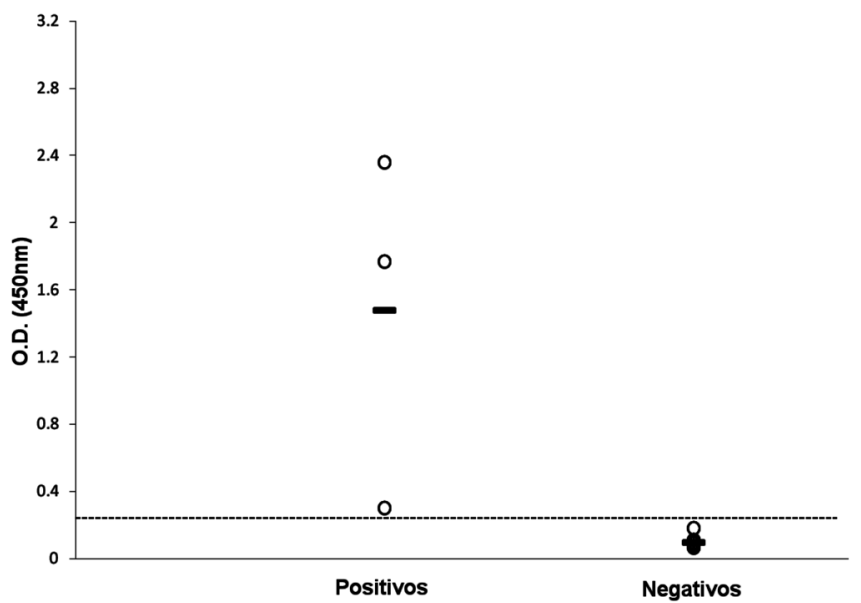

Fig.3. Distribuição dos resultados individuais dos soros de canídeos silvestres submetidos à ELISA indireto para detecção de anticorpos específicos anti-Leishmania, usando o conjugado Proteína A com peroxidase na diluição de 1:16.000. Cada círculo representa o resultado de um animal testado, e as barras a média de cada grupo, positivo ou negativo. A linha tracejada indica o cut-off calculado, usando o método de Frey et al. (1998).

exame sorológico não detectou a presença de anticorpos anti-Leishmania sp. nos dois C. thous do PZGV.

As densidades ópticas (DO) médias das amostras de todos os canídeos silvestres foram maiores quando o conjugado utilizado foi a proteína A (DO média $=0,546$ ) em comparação com o anticorpo anti-IgG de cão (D0 média $=0,251$ ). No ELISA com o anti-IgG de cão diluído a 1:25.000 (Fig.1), os valores das D0s dos animais positivos e negativos variaram entre 0,899 e 0,300 (Média $=0,531$; desvio padrão $=0,307$ ) e $0,153-0,087$ (Média $=0,110$; desvio padrão $=0,040$ ) com o valor da média das DOs do branco de 0,045 . No ELISA com a proteína A na diluição de 1:8.000 (Fig.2), os valores da leitura dos soros positivos foram de 3,183-2,286 (Média = 1,961; desvio padrão $=0,634$ ) e 
0,278-0,071 (Média $=0,126$; desvio padrão $=0,108$ ) com a leitura do branco de 0,039. O ELISA com proteína A a 1:16.000 (Fig.3) resultou em leituras dos soros positivos de 2,359-1,769 (Média = 1,475; desvio padrão = 0,417) e 0,182-0,066 (Média $=0,095$; desvio padrão $=0,072$ ) para os negativos, sendo o valor da média das DOs dos brancos de 0,042.A média das DOs das amostras negativas foi 4,8 vezes mais baixa do que a média das DOs das amostras positivas no ensaio com o conjugado anti-IgG de cão e 15,5 vezes mais baixa nos testes com a Proteína A independente das diluições realizadas.

Ambos os ensaios apresentaram altas repetitividades tanto para o controle positivo quanto para o controle negativo nos diferentes testes de ELISA indireto com ambos os conjugados.

O teste de Western blotting evidenciou a detecção de 22 bandas em cada amostra de soro de três $C$. brachyurus soropositivos nos testes de ELISA, com destaque para bandas de peso molecular 19, 22, 24, 45 e $66 \mathrm{kDa}$, presentes em todos os animais com soropositividade nos ELISAs (Quadro 4). As bandas de $212 \mathrm{kDa}, 32 \mathrm{kDa}$ e $23 \mathrm{kDa}$ foram constatadas apenas nos animais com soropositividade mais intensa, tais como os indivíduos 01 e 05 . Nenhuma banda foi detectada pelas amostras de soro dos animais soronegativos aos ELISAs. 0 ELISA indireto com a Proteína A apresentou alta concordância com os resultados do WB (Kappa $=1 ; \mathrm{p}<0,001)$, enquanto o teste com o conjugado anti-IgG de cão apresentou uma concordância moderada (Kappa $=0,8 ; \mathrm{p}<0,0015)$.

\section{DISCUSSÃO}

Os testes ELISA padronizados no presente estudo mostraram-se adequados ao suporte laboratorial no diagnóstico de um animal com suspeita clínica de infecção por Leishmania chagasi. A maior capacidade de discernimento entre soros positivos e negativos foi apresentada pelo ELISA padronizado com Proteína A, conforme definido pelo valor da razão das médias de DO positivos / DO negativos $(15,5)$, em comparação com o resultado do ensaio com anti-IgG de cão (razão 4,8).

A maior reatividade da proteína A (média geral de DO $0,546)$ no ELISA indireto pode ser explicada por sua alta afinidade pelos anticorpos da classe IgG presentes no soro em resposta específica à infecção (Lima et al. 2005). A Proteína A pode reagir tanto com as subclasses IgG1, IgG2a, IgG2b e IgG3, se ligando à cadeia pesada do anticorpo, quanto com os anticorpos das classes IgM e IgA caninas (Goudswaard et al. 1978, Lima et al. 2005). Dessa forma, animais na fase aguda da infecção, ainda não detectáveis em testes de triagem com métodos baseados no uso de anti-IgG de cão doméstico, podem ser identificados no ensaio padronizado com a Proteína A, que ainda parece detectar uma maior abrangência de moléculas de IgGs. De fato, no presente estudo, tanto a reatividade geral (DO 0,251) quanto à razão D0 positivos / DO negativos $(4,8)$ foram menores no ELISA com conjugado anti-IgG de cão.

O conjugado anti-IgG de cão utilizado reconhece a cadeia pesada do anticorpo que pode apresentar variações de sequência aminoacídica em diferentes espécies, ou mesmo em diferentes isotipos de uma mesma espécie (Silva et al. 2005a). O conjugado anti-IgG de cão é citado na padronização de testes sorológicos em diversas espécies de canídeos selvagens nativas do Brasil (Courtenay et al. 2002, Curi et al. 2006, Luppi et al. 2008) ou exóticas (Mancianti et al. 1994). Em um estudo semelhante, na investigação de reatividade sorológica no teste ELISA anti-Toxoplasma gondii com amostras de soros de $C$. brachyurus, os resultados com diferentes conjugados enzimáticos, tais como a Proteína $\mathrm{A}$, conjugado anti-IgG de cão e conjugado anti-IgG de C. brachyurus foram equivalentes (Silva et al. 2005a).

Um Chrysocyon brachyurus (indivíduo 7) negativo nos testes de PCR e IFI parta LV foi positivo apenas no ELISA com o conjugado anti-IgG de cão, sendo soronegativo nos testes com Proteína A e WB. Apesar do exame clínico desse animal evidenciar esplenomegalia e linfadenomegalia, o resultado foi estar associado a uma reação cruzada com outro patógeno, uma vez que mesmo no WB, que é um teste mais sensível que o ELISA, o resultado manteve-se negativo. Reações cruzadas entre Leishmania spp. e Trypanosoma cruzi com a utilização de conjugados homólogos têm sido descritas (Luciano et al. 2009), sendo de grande importância a determinação da especificidade dos ensaios sorológicos.

A soronegatividade de Lycalopex vetulus (indivíduo 8) com positividade em PCR e IFI prévios para LV pode indicar que esse animal pode ter soroconvertido para negatividade durante o tempo decorrido entre a realização daqueles testes e os ELISAs do presente estudo. Este resultado pode sugerir a cura espontânea, uma vez que o animal apresentava-se clinicamente hígido. Outra possibilidade para esse resultado é que a espécie pode não apresentar resposta humoral expressiva durante a infecção por Leishmania. Esse aspecto deve ser estudado e compreendido, uma vez que em cães domésticos a resposta imune celular predominante sobre a resposta humoral é associada ao perfil de resistência e baixa transmissibilidade da infecção (Pinelli et al. 1994, Travi et al. 2001). Se o indivíduo 08 apresenta um perfil de resistência imunológica, na qual a resposta celular mediada por linfócitos T combate o crescimento de Leishmania sp, com níveis baixos de IgGs anti-Leishmania, seu papel como reservatório da doença deve ser bem situado, principalmente no âmbito de saúde pública. Neste caso, um estudo para definir a real transmissibilidade de parasito ao vetor por esses animais torna-se imprescindível. Outro aspecto que deve ser bem definido é a adequação desses conjugados à espécie, para que não haja subdiagnóstico em decorrência de um conjugado de baixa afinidade pela molécula de imunoglobulina de $L$. vetulus utilizado no soroteste. Estudos com um número maior de animais buscando avaliar essa hipótese devem ser realizados.

Os dois $C$. thous, cativos em área não endêmica para a $L V$, apresentaram-se negativos ao ELISA indireto com ambos os conjugados, assim como no teste WB. Mesmo sendo comum o achado de canídeos parasitados por Leishmania sp. (Silva et al. 2000, Gomes et al. 2002, Luppi et al. 2008, Lima et al. 2009, Souza et al. 2010), dentre estes C. thous (Courtenay et al. 1996), pelo menos um estudo aponta que esta espécie, comparada aos cães domésticos, teve um papel irrelevante como reservatório da doença na Ilha de Marajó, Pará, Brasil (Courtenay et al. 2002). 
Nos ensaios de WB foram detectadas cinco bandas (66 kDa, $45 \mathrm{kDa}, 24 \mathrm{kDa}, 22 \mathrm{kDa}, 19 \mathrm{kDa}$ ) comuns aos três animais soropositivos no ELISA. Entretanto, as bandas de 212 $\mathrm{kDa}, 32 \mathrm{kDa}$ e $23 \mathrm{kDa}$ foram constatadas apenas nos animais com soropositividade mais intensa, tais como os indivíduos 01 e 05 . A banda de $32 \mathrm{kDa}$ já foi descrita em ensaios com soros de cães domésticos infectados com L. chagasi (Mancianti, Pedonesi \& Poli 1996, Oliveira et al. 2005, Silva et al. 2005b), inclusive antes da soroconversão de animais com parasitismo tecidual comprovado (Silva et al. 2005b). Todas as bandas detectadas pelo soro de C. brachyurus $\mathrm{n}^{-}$ 05 , comprovadamente infectado, devem ser avaliadas com maior acurácia em um estudo com um número maior de animais naturalmente parasitados e diferentes perfis clínicos e imunológico, para possível emprego do(s) antígeno(s) imunodominantes(s) como ferramenta de diagnóstico e provavelmente de imunoprofilaxia. Outra possibilidade a ser investigada é que os antígenos imunodominantes segundo a resposta humoral de canídeos silvestres difiram daqueles definidos em estudos de cães domésticos.

A morte de um S. venaticus e uma L. vetulus na FZB, descrita por Luppi e colaboradores (2008), assim como soropositividade de mais três $C$. brachyurus confirmada pelo teste WB desenvolvido no presente estudo, demonstram a importância da continuidade dos estudos e o estabelecimento de estratégias de prevenção e controle da LV para as espécies silvestres de área endêmica em conservação $e x$ situ.

Com a comprovação da susceptibilidade de canídeos silvestres à infecção por Leishmania, pelas evidências de doença clínica e óbito, as medidas preventivas recomendadas para cães domésticos devem ser aplicadas também aos canídeos cativos em áreas endêmicas. 0 monitoramento clínico e a investigação sorológica do plantel de canídeos das instituições conservacionistas devem ser realizados periodicamente.

Com base nos resultados deste estudo, os ELISAs padronizados com ambos os conjugados são capazes de diferenciar canídeos soropositivos dos soronegativos para imunoglobulinas anti-Leishmania, portanto podem auxiliar nas medidas de controle da doença. Contudo, apesar do ensaio com a Proteína A ter se mostrado adequado a testes de triagem para estudos sobre a resposta imune dos hospedeiros silvestres à infecção por Leishmania sp., o desenvolvimento de conjugados com anticorpos espécie-específicos deve ser almejado para padronização de sorotestes mais precisos e designados para as diferentes espécies silvestres.

Agradecimentos.- Ao CNPq e FAPESB, pelo auxílio financeiro que possibilitou a realização do estudo; à FZB-BH e ao PZGV-BA, pela disponibilização dos animais.

\section{REFERÊNCIAS}

Almeida A.B.P.F., De Paula D.A.J., Colodel E.M., Dutra V., Nakazato L. \& Sousa V.R.F. 2011. Leishmaniose visceral e hepatite infecciosa em cachorro-vinagre mantido em cativeiro no Brasil: relato de caso. Ciências Agrárias 32:333-338.

Brasil 2005. Guia de Vigilância Epidemiológica. Departamento de Vigilância Epidemiológica, Secretaria de Vigilância em Saúde, Ministério da Saúde, Brasília, DF. 815p.
Courtenay O., Santana E.W., Johnson P.J., Vasconcelos I.A.B. \& Vasconcelos A.W. 1996. Visceral leishmaniasis in the hoary zorro Dusicyon vetulus: A case of mistaken identity. Trans. R. Soc. Trop. Med. Hyg. 90:498-502.

Courtenay O., Quinnel R.J., Garcez L.M. \& Dye C. 2002. Low infectiousness of a wildlife host of Leishmania infantum: the crab-eating fox is not important for transmission. Parasitology 125:407-414.

Curi N.H.A., Miranda I. \& Talamoni A.S. 2006. Serologic evidence of Leishmania infection in free-ranging wild and domestic canids around a Brazilian National Park. Mem. Inst. Oswaldo Cruz 101:99-101.

Dantas-Torres F. 2006. Final comments on an interesting taxonomic dilemma: Leishmania infantum versus Leishmania infantum chagasi. Mem. Inst. Oswaldo Cruz 101:929-930.

Frey A., Di Canzio J. \& Zurakowski D.A. 1998. A statistically defined endpoint 335 titer determination method for immunoassays. J. Immunol. Methods 221:35-41.

Gomes R.B., Brodskyn C., Oliveira C.I., Costa J.M.L., Miranda J.C., Caldas A., Valenzuela J.G., Barralnetto M. \& Barral A. 2002. Seroconversion against Lutzomyia longipalpis saliva concurrent with the development of anti-Leishmania chagasi delayed-type hypersensitivity. J. Infect. Dis. 186:1530-1534.

Gomes M.S. 2006. Carnivora - Canidae (Lobo-guará, Cachorro-do-mato, Raposa-do-campo), p.492-504. In: Cubas Z.S., Silva J.C. \& Dias J.L.C. (Eds), Tratado de Animais Selvagens. Editora Roca, São Paulo.

Goudswaard J., Vander Donk J.A., Noordzij A., Van Dam R.H. \& Vaerman J.P. 1978. Protein A reactivity of various mammalian immunoglobulins. Scand. J. Immunol. 8:21-28.

Jusi M.M.G., Starke-Buzetti W.A., Oliveira T.M.F.S., Tenório M.S., Sousa L.O. \& Machado R.Z. 2011. Molecular and serological detection of Leishmania spp. in captive wild animals from Ilha Solteira, SP, Brazil. Revta. Bras. Parasitol. Vet. 20:219-222.

Kelly P.J., Tagwira M., Matthewman L., Mason P.R. \& Wright E.P. 1993. Reactions of sera from laboratory, domestic and wild animals in Africa with protein A and a recombinant chimeric protein AG. Comp. Immunol. Microbiol. Infect. Dis. 16:299-305.

Lima V.M.F., Biazonno L., Silva A.C., Corrêa A.P.F.L. \& Luvizotto M.C.R. 2005. Serological diagnosis of visceral leishmaniasis by an enzyme immunoassay using protein A in naturally infected dogs. Pesq. Vet. Bras. 25:215218.

Lima V.M.F., Fattori K.R., Michelin A.F., Nogueira F.S. \& Souza L.O.E. 2009. Evidence of Leishmania spp. antibodies and DNA in bush dog (Speothos venaticus) in Brazil. J. Zoo Wildl. Med. 40:91-94.

Luciano R.M., Lucheis S.B.,Troncarelli M.Z., Luciano D.M. \& Langoni H. 2009. Avaliação da reatividade cruzada entre antígenos de Leishmania spp e Trypanosoma cruzi na resposta sorológica de cães pela técnica de imunofluorescência indireta (RIFI). Braz. J. Vet. Res. Anim. Sci. 46:81187.

Luppi M., Malta M., Silva T., Silva F., Motta R.O.C., Miranda I., Ecco R. \& Santos R. 2008. Visceral leishmaniasis in captive wild canids in Brazil. Vet. Parasitol. 155:146-151.

Mancianti F., Mignone W. \& Galestri F. 1994. Serologic survey for leishmaniasis in free-living red foxes (Vulpes vulpes) in Italy. J. Wildl. Dis. 30:454-456.

Mancianti F., Pedonese F. \& Poli A. 1996. Evaluation of dot enzyme-linked immunosorbent assay (dot-ELISA) for the serodiagnosis of canine leishmaniosis as compared with indirect immunofluorescence assay, Vet. Parasitol. 65:1-9.

Mauricio I.L., Howard M.K., Stothard J.R. \& Miles M.A. 1999. Genetic diversity in the Leishmania donvani complex. Parasitology 119:237-246.

Oliveira L.S., Julião F.S., Souza V.M.M., Freitas D.S., Souza B.M.P.S., Paule B.J.A., Aguiar P.H.P., Barrouin-Melo S.M. \& Franke C.R. 2005. A utilização da Imunofluorescência Indireta no diagnóstico de rotina da Leishmaniose Visceral Canina e suas implicações no controle da doença. Ciênc. Anim. Bras., Goiânia, 6:41-48.

Oliveira T.M.F.S., Furuta P.L., Carvalho D.C. \& Machado R.Z. 2008. A study of cross-reactivity in serum samples from dogs positive for Leishmania sp, Babesia canis and Ehrlichia canis in enzyme-linked immunosorbent 
assay and indirect fluorescent antibody test. Revta Bras. Parasitol. Vet. 17:7-11.

Paranhos-Silva M., Freitas L.A.R., Santos W.C., Grimaldi Jr G., Pontes-De-Carvalho L.C. \& Oliveira-Dos-Santos A.J. 1996. A cross-sectional serodiagnostic survey of canine leishmaniasis due to Leishmania chagasi. Am. J. Trop. Med. Hyg. 55:39-44.

Pinelli E., Killick-Kendrick R., Wagenaar J., Bernadina W., Real G. \& Ruitenberg J. 1994. Cellular and humoral immune responses in dogs experimentally and naturally infected with Leishmania infantum. Infect. Immun. 62:229-35.

Rebouças M.F., Portela R.W., Lima D.D., Loureiro D., Bastos B.L., Moura-Costa L.F., Vale V.L., Miyoshi A., Azevedo V. \& Meyer R. 2011. Corynebacterium pseudotuberculosis secreted antigen-induced specific gamma-interferon production by peripheral blood leukocytes: potential diagnostic marker for caseous lymphadenitis in sheep and goats. J. Vet. Diagn. Invest. 23:213-220.

Ruas J.L., Farias N.A.R., Soares M.P. \& Brum J.G.W. 2003. Babesia sp. em graxaim do campo (Lycalopex gymnocercus) no sul do Brasil. Arqs Inst. Biológico, São Paulo, 70:113-114.

Shrout P. 1998. Measurement reliability and agreement in psychiatry. Statist. Meth. Med. Res. 7:301-317.

Silva E.S., Pirmez C., Gontijo C.M.F., Fernandes O. \& Brazil R.P. 2000. Visceral leishmaniasis in the crab-eating fox (Cerdocyon thous) in south-east Brazil. Vet. Rec. 147:421-422.

Silva D.A.O., Vitaliano S.N., Mineo T.W.P., Ferreira† R.A., Bevilacquał E \&
Mineo J.R. 2005a. Evaluation of homologous, heterologous, and affinity conjugates for the serodiagnosis of Toxoplasma gondii and Neospora caninum in maned wolves (Chrysocyon brachyurus). J. Parasitol. 91: 1212-1216

Silva A.V.M., De Paula A.A., Cabrera M.A.A. \& Carrera J.C.A. 2005b. Leishmaniose em cães domésticos: aspectos epidemiológicos. Cad. Saúde Pública, Rio de J., 21:324-328.

Solano-Gallego L., Rodriguez A., Iniesta L., Arboix M., Portús M. \& Aalberola J. 2003. Detection of anti-Leishmania immunoglobulin G antibodies in urine specimens of dogs with leishmaniasis. Clin. Diagn. Lab. Immunol. 10:849-855

Souza N.P., Almeida A.B.P.F., Freitas T.P.T., Paz R.C.R., Dutra V., Nakazato L. \& Sousa V.R. 2010. Leishmania (Leishmania) infantum chagasi em canídeos silvestres mantidos em cativeiro, no Estado de Mato Grosso. Revta Soc. Bras. Med. Trop. 43:333-335.

Stöbel K., Schönberg A. \& Staak C. 2002. A new non-species dependent ELISA for detection of antibodies to Borrelia burgdorferi in zoo animals. Int. J. Med. Microbiol. 33:88-99.

Travi B.L., Tabares C.J., Cadena H., Feroo C. \& Osorio Y. 2001. Canine visceral leishmaniasis in Colombia: Relationship between clinical and parasitologic status and infectivity for sand flies. Am. J. Trop. Med. Hyg. 64:119-124.

Zrzavy J. \& Ricankova V. 2004. Phylogeny of recent canidae (Mammalia, Carnivora): Relative reliability and utility of morphological and molecular datasets. Zool. Scripta 33:311-333. 